\title{
Fetal Sinus Bradycardia Is Associated with Congenital Hypothyroidism: An Infant with Ectopic Thyroid Tissue
}

\author{
Aya Nakanomori, ${ }^{1}$ Nobuhiko Nagano, ${ }^{1}$ Ayako Seimiya, ${ }^{1}$ Aya Okahashi ${ }^{1}$ and \\ Ichiro Morioka ${ }^{1}$
}

${ }^{1}$ Department of Pediatrics and Child Health, Nihon University School of Medicine, Tokyo, Japan

\begin{abstract}
Hypothyroidism is rarely included in the differential diagnosis for fetal sinus bradycardia. We report an infant with congenital hypothyroidism caused by ectopic thyroid tissue, who showed antenatal bradycardia. The baseline fetal heart rate was $100-110$ bpm at 30 weeks of gestation, and fetal echocardiography revealed sinus bradycardia but no cardiac anomalies. Maternal thyroid function was normal (thyroidstimulating hormone [TSH] $2.03 \mu \mathrm{lU} / \mathrm{ml}$, free T3 $2.65 \mathrm{pg} / \mathrm{ml}$, and free T4 $0.99 \mathrm{ng} / \mathrm{dl}$ ) when measured at 31 weeks of gestation. Her serum anti SS-A and SS-B antibodies, anti-thyroglobulin, and microsomal antibodies were negative. A male infant without cardiac anomalies was delivered at 35 weeks and 4 days of gestation and admitted for prematurity and respiratory distress syndrome. The infant's heart rate was 70-110 bpm (normal: 120-160 bpm) on admission. On 8 days of age, thyroid function tests revealed that the infant had severe hypothyroidism (TSH $903.3 \mu \mathrm{lU} / \mathrm{ml}$, free T3 $1.05 \mathrm{pg} / \mathrm{ml}$, and free T4 $0.26 \mathrm{ng} / \mathrm{dl}$ ). The prolonged jaundice assumed to be due to hypothyroidism. Oral levothyroxine sodium hydrate $(10 \mu \mathrm{g} / \mathrm{kg} /$ day) was immediately started on day 8 . After the treatment, the heart rate was gradually increased to 130-140 bpm as the infant's thyroid function was improved (TSH $79.8 \mu \mathrm{lU} / \mathrm{ml}$, free T3 $2.95 \mathrm{pg} / \mathrm{dl}$, and free T4 $1.66 \mathrm{ng} / \mathrm{dl}$ on day 22). The infant was diagnosed ectopic thyroid tissue because of the high thyroglobulin level $(85.9 \mu \mathrm{g} / \mathrm{l})$. In conclusion, congenital hypothyroidism should be included in the differential diagnosis in cases of fetal bradycardia without cardiac anomalies or maternal autoimmune diseases.
\end{abstract}

Keywords: congenital hypothyroidism; ectopic thyroid tissufree; fetal bradycardia; levothyroxine sodium hydrate; maternal autoimmune disease

Tohoku J. Exp. Med., 2019 August, 248 (4), 307-311. (C) 2019 Tohoku University Medical Press

\section{Introduction}

Fetal bradycardia is defined as a heart rate less than $110 \mathrm{bpm}$ (Macones et al. 2008). The main mechanisms of perinatal bradycardia are sinus bradycardia, complete heart block, and functional atrioventricular block (Jaeggi and Öhman 2016). Fetal complete heart block is strongly associated with maternal connective tissue disease, such as Sjögren's syndrome and systemic lupus erythematosus, and the presence of maternal anti-SS-A/Ro or anti-SS-B/La antibodies also increases the risk of complete heart block in the fetus (Izmirly et al. 2011). A pregnant woman with fetal bradycardia should undergo testing for autoimmune disease.

Here we report prenatal sinus bradycardia in an infant whose mother did not have autoimmune disease. Fetal sinus bradycardia may be secondary to fetal distress, placental insufficiency, anatomic abnormality of the sinus node, or long QT syndrome (Kleinman and Nehgme 2004;
Jaeggi and Öhman 2016). A previous study has reported that congenital hypothyroidism was not predicted from a decreased fetal heart rate (Miyai et al. 1979). On the other hand, there are some cases that congenital hypothyroidism presented with fetal bradycardia, such as autoimmune thyroiditis with severe hypothyroidism and severe congenital hypothyroidism induced by maternal blocker antibodies (Kara et al. 2013; Marzuillo et al. 2016). In general, however, hypothyroidism is rarely included in the differential diagnosis for fetal sinus bradycardia.

Our patient had congenital hypothyroidism with fetal bradycardia, and the heart rate of the patient was increased when treatment for hypothyroidism was started after delivery. We therefore propose that the fetal bradycardia is attributed in this case to hypothyroidism. The institutional review board of Nihon University Itabashi Hospital approved this case study with informed consent (approval number: RK-190709-5).

Received July 17, 2019; revised and accepted August 16, 2019. Published online August 28, 2019; doi: 10.1620/tjem.248.307.

Correspondence: Nobuhiko Nagano, M.D., Ph.D., Department of Pediatrics and Child Health, Nihon University School of Medicine,

30-1 Oyaguchi, Kami-Cho, Itabashi-ku, Tokyo 173-8610, Japan.

e-mail: nagano.nobuhiko@ nihon-u.ac.jp 


\section{Case Report}

A 31-year-old primigravida with an unremarkable past medical history was admitted for threatened preterm labor at 30 weeks of gestation. The baseline fetal heart rate was 100-110 bpm (<3\% percentile; Fig. 1a). For comparison, normal fetal heart rate is shown in Fig. 1b (140-160 bpm). Fetal echocardiography revealed sinus bradycardia but no cardiac anomalies. The mother has no signs of thyroid disease and no history of hysterosalpingography or excess iodine. Her thyroid function was normal (thyroid-stimulating hormone [TSH] $2.03 \mu \mathrm{IU} / \mathrm{ml}$, free T3 $2.65 \mathrm{pg} / \mathrm{ml}$, and free T4 $0.99 \mathrm{ng} / \mathrm{dl}$ ) at 31 weeks of gestation. Serum anti SS-A and SS-B antibodies, anti-thyroglobulin, and microsomal antibodies were negative. A male infant was delivered by spontaneous vaginal delivery after premature rupture of membranes at 35 weeks and 4 days of gestation and admitted for prematurity and respiratory distress syndrome. The Apgar scores were six and nine at one and five minutes after birth. The heart rate was $70-110 \mathrm{bpm}$ on admission. The electrocardiogram showed sinus bradycardia but no other abnormal findings, such as an irregular RR or prolonged QT interval (Fig. 1c). Echocardiography on admission did not indicate a cardiac anomaly or any signs of heart failure. Laboratory findings did not reveal a cause of bradycardia, such as electrolyte imbalance (Table 1).

\section{Hospital course}

Artificial surfactant was administered, and then ventilation was started for respiratory distress syndrome. Respiratory status was improved gradually, and the patient was extubated on 1 day of age. Oxygen supplementation was no longer needed by 7 days of age. The infant was noted to have hyperbilirubinemia, which persisted despite phototherapy being started on 3 days of age. Routine neonatal screening was performed on 5 days of age and showed decreased thyroid function (TSH $>81.8 \mu \mathrm{IU} / \mathrm{ml}$ and free T4 $0.28 \mathrm{ng} / \mathrm{dl}$ ). On 8 days of age, thyroid function tests at our hospital revealed that the infant had severe hypothyroidism (TSH $903.3 \mu \mathrm{IU} / \mathrm{ml}$, free T3 $1.05 \mathrm{pg} / \mathrm{ml}$, and free T4 0.26 $\mathrm{ng} / \mathrm{dl}$ ). Radiographic examination of the lower limbs showed that both knee epiphyses were absent (Fig. 2a: this case and 2b: a normal newborn). Furthermore, ultrasonography revealed that the thyroid gland was not at the orthotopic site in the neck (Fig. 2c: this case and 2d: a normal infant). The thyroglobulin level in our case was $85.9 \mu \mathrm{g} / 1$. A previous study has reported the thyroglobulin level ranged from $<1.0$ to $18.7 \mu \mathrm{g} / \mathrm{l}$ in cases with athyreosis and the level from 12.2 to $123 \mu \mathrm{g} / \mathrm{l}$ in cases with ectopic thyroid tissue (Beltrao et al. 2010). This case was, therefore, diagnosed as ectopic thyroid tissue based on the thyroglobulin level. The prolonged jaundice assumed to be a symptom of hypothyroidism. There were no other symptoms of hypo-

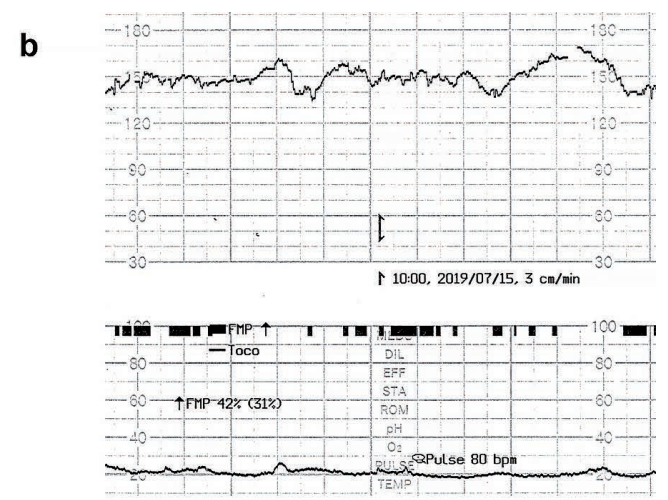

\section{thyroidism, including constipation, dry skin, poor general}

a
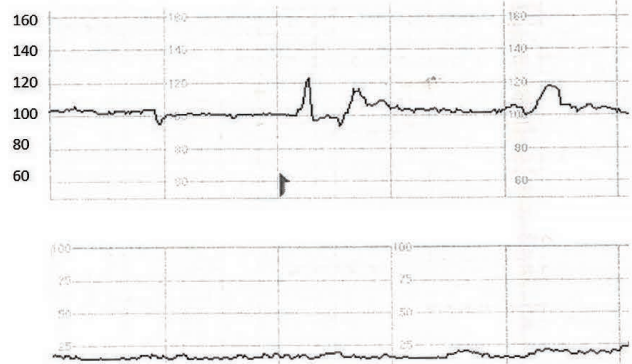

C

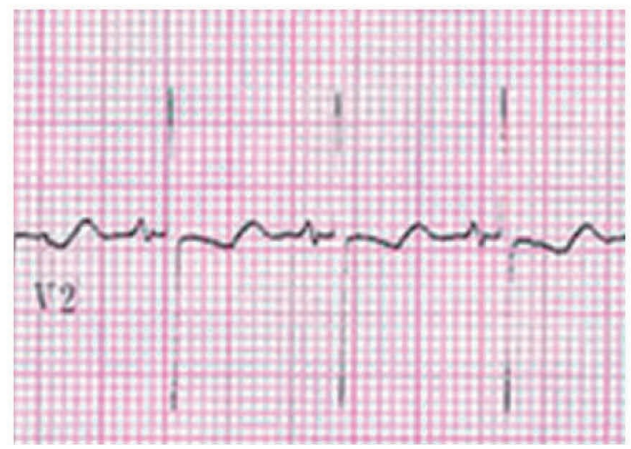

Fig. 1. The cardiotocogram and electrocardiogram on admission.

a. The cardiotocogram at 30 weeks of gestation in our case. The fetal heart rate baseline is $100-110 \mathrm{bpm}$. b. The cardiotocogram at 38 weeks of gestation in a normal fetus. The fetal heart rate baseline is $140-160 \mathrm{bpm}$. c. The electrocardiogram with sinus bradycardia on admission in our case (110 bpm). 
Table 1. Laboratory data on admission.

\begin{tabular}{|c|c|c|}
\hline WBC & 10,500 & $/ \mu 1$ \\
\hline $\mathrm{RBC}$ & 370 & $\times 10^{4} / \mu 1$ \\
\hline Hemoglobin & 14.1 & $\mathrm{~g} / \mathrm{dl}$ \\
\hline Plt & 31.3 & $\times 10^{4} / \mu 1$ \\
\hline T-bil & 2.17 & $\mathrm{mg} / \mathrm{dl}$ \\
\hline D-bil & 0.55 & $\mathrm{mg} / \mathrm{dl}$ \\
\hline AST & 53 & $\mathrm{U} / 1$ \\
\hline ALT & 6 & $\mathrm{U} / 1$ \\
\hline LDH & 453 & $\mathrm{U} / 1$ \\
\hline ALP & 627 & $\mathrm{U} / 1$ \\
\hline $\mathrm{CK}$ & 644 & $\mathrm{U} / 1$ \\
\hline BUN & 9.4 & $\mathrm{mg} / \mathrm{dl}$ \\
\hline $\mathrm{Cr}$ & 0.65 & $\mathrm{mg} / \mathrm{dl}$ \\
\hline $\mathrm{Na}$ & 140 & $\mathrm{mmol} / \mathrm{l}$ \\
\hline K & 3.8 & $\mathrm{mmol} / \mathrm{l}$ \\
\hline $\mathrm{Cl}$ & 108 & $\mathrm{mmol} / \mathrm{l}$ \\
\hline $\mathrm{Ca}$ & 8.6 & $\mathrm{mg} / \mathrm{dl}$ \\
\hline $\mathrm{P}$ & 7.1 & $\mathrm{mg} / \mathrm{dl}$ \\
\hline $\mathrm{Mg}$ & 2.2 & $\mathrm{mg} / \mathrm{dl}$ \\
\hline TP & 4.2 & $\mathrm{~g} / \mathrm{dl}$ \\
\hline $\mathrm{Alb}$ & 2.9 & $\mathrm{~g} / \mathrm{dl}$ \\
\hline CRP & $<0.1$ & $\mathrm{mg} / \mathrm{dl}$ \\
\hline IgG & 501 & $\mathrm{mg} / \mathrm{dl}$ \\
\hline $\operatorname{IgA}$ & 3 & $\mathrm{mg} / \mathrm{dl}$ \\
\hline $\operatorname{IgM}$ & 9 & $\mathrm{mg} / \mathrm{dl}$ \\
\hline
\end{tabular}

condition, cold extremities, and delayed closure of posterior fontanelle. However, the infant's weight had not return to the birth weight by 8 days of age. Oral levothyroxine sodium hydrate $(10 \mu \mathrm{g} / \mathrm{kg} /$ day $)$ was started from 8 days of age. After the treatment, the infant's heart rate was gradually increased to $130-140 \mathrm{bpm}$ as his thyroid function was improved (TSH $79.8 \mu \mathrm{IU} / \mathrm{ml}$, free T3 $2.95 \mathrm{pg} / \mathrm{dl}$, and free T4 $1.66 \mathrm{ng} / \mathrm{dl}$ on day 22). The hyperbilirubinemia was also improved gradually after treatment was initiated. The infant showed sufficient weight gain and was discharged on 27 days of age (Fig. 3).

\section{Discussion}

This case demonstrates that congenital hypothyroidism may cause fetal sinus bradycardia. We therefore suggest that congenital hypothyroidism should be included in the differential diagnosis for fetal sinus bradycardia.

The fetal thyroid gland appears by 10 weeks of gestation, by which time it has already developed the ability to concentrate radioiodine and synthesize iodothyronines (Fisher and Klein 1981; Burrow et al. 1994). The fetal pituitary gland also develops at about the same time, when TSH and T4 are measurable in fetal serum. At gestational 18-22 weeks, the pituitary and serum TSH concentrations start to increase. Peak serum TSH levels occur at gestational 20-24 weeks and gradually decrease until term. In contrast, fetal serum T4 and free T4 concentrations were increased from mid-gestation, peaking between 20 and 30 weeks' gestation. In our case, the fetal bradycardia became noticeable from 30 weeks' gestation. We suspect that congenital hypothyroidism in a fetus manifests as bradycardia with a low T4 from that time onwards. However, little has been reported on the relationship between fetal bradycardia and congenital hypothyroidism. The human placenta acts as a barrier to maternal-fetal transfer of thyroid hormones (Fisher 1997). In the past, the placenta was thought to be impermeable to thyroid hormones (Fisher and Klein 1981). However, Vulsma et al. (1989) showed that the cord serum total T4 level in the human fetus with thyroid agenesis is approximately $30 \%$ of the concentration in the normal fetus. It is presumed that there is limited but significant T4 transfer between the mother and fetus via the placenta. We speculate that the reason why there are so few reports of congenital hypothyroidism manifesting as fetal bradycardia is that thyroid function in the fetus is supplemented by maternal thyroid hormones. Moreover, it was reported that infants with $\mathrm{TSH}>100 \mu \mathrm{IU} / \mathrm{ml}$ have significantly slower heart rate than those with lower TSH levels (Öner et al. 2015). Although there are limited relevant postnatal data, we consider that neonates with markedly high TSH might have had bradycardia at the fetal stage. It can be inferred from the present case that bradycardia as a symptom of low T4 at the fetal stage occurs because placental transfer of thyroid hormones is insufficient to fully supplement fetal thyroid function. Congenital hypothyroidism should be considered when a fetus shows bradycardia in the absence of a cardiac anomaly or maternal autoimmune disease.

Thyroid hormone is critical for normal growth and brain development, and hypothyroidism in infancy is a leading cause of intellectual impairment. If the diagnosis of hypothyroidism is made and treatment started within a few weeks of birth, the neurodevelopmental outcome is generally normal (LaFranchii and Austin 2007). Most newborns with congenital hypothyroidism do not have a distinctive appearance and the symptoms of hypothyroidism are not specific; namely, early diagnosis of hypothyroidism is challenging. Congenital hypothyroidism became easier to diag- 


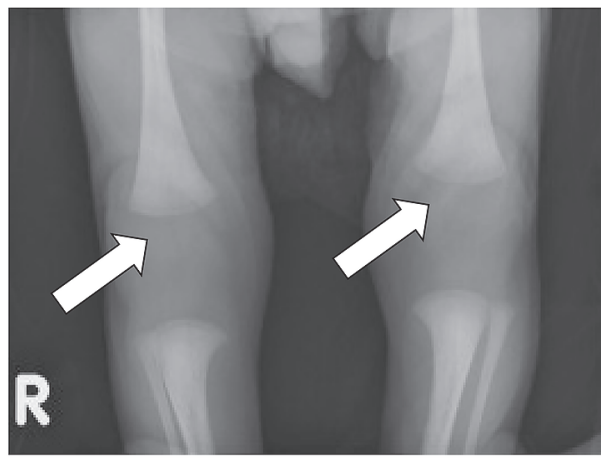

b

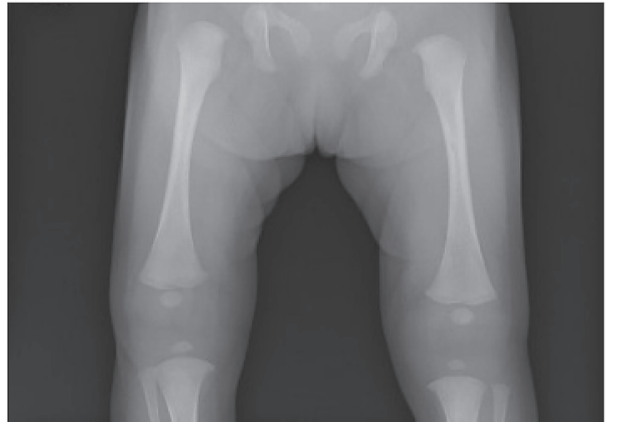

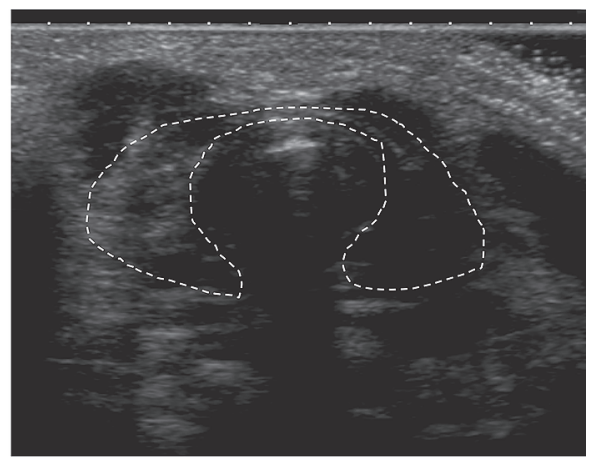

d

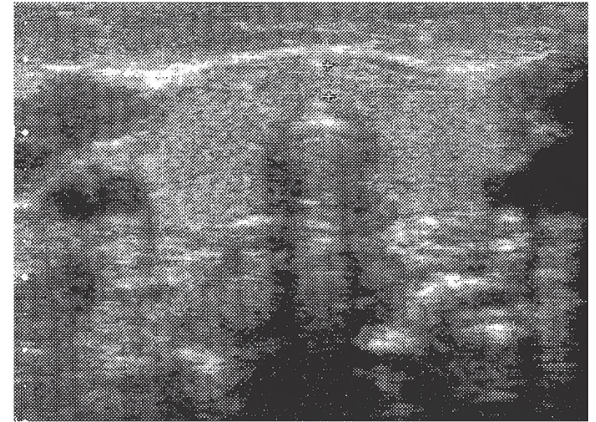

Fig. 2. Radiography of lower limbs and ultrasonography of neck.

a. Radiography of lower limbs of our case at 8 days of age: absence of both knee epiphyses (Arrows indicate abnormal findings). b. Radiography of lower limbs of a normal newborn at 21 days of age: presence of both knee epiphyses. c. Ultrasonography of neck of our case at 8 days of age: the thyroid gland is not at the orthotopic site. d. Ultrasonography of neck of a normal infant at 1 month of age: the thyroid gland is at the orthotopic site.

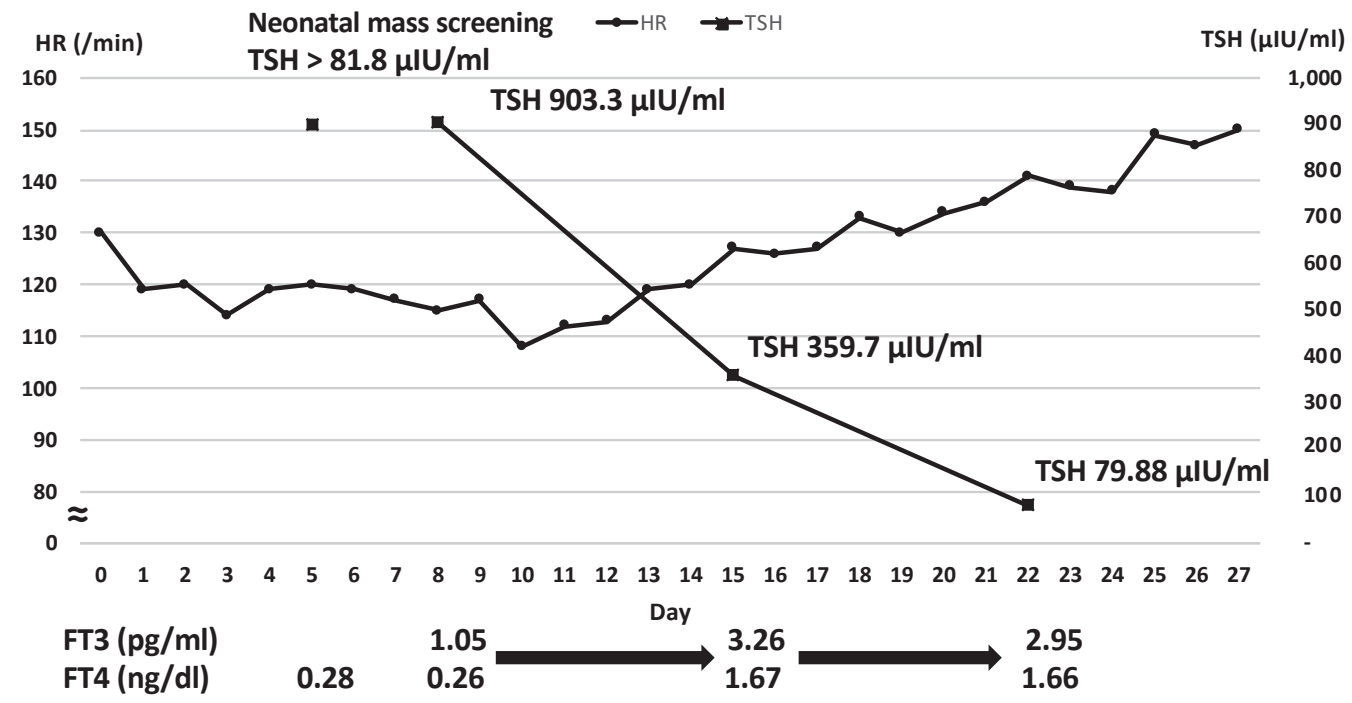

Brothotherpy

Levothyroxine sodium hydrate $10 \mu \mathrm{g} / \mathrm{kg} /$ day

Fig. 3. Hospital course.

The heart rate was gradually increased as his thyroid function was improved.

FT3, free T3; FT4, free T4.

nose when neonatal screening was introduced. However, the neonatal screening sample must be sent to a centralized laboratory for examination, and it takes time to the result. We believe that consideration of congenital hypothyroidism when sinus bradycardia is detected in a fetus could aid early diagnosis.

In conclusion, we report a case of congenital hypothyroidism caused by ectopic thyroid tissue that manifested as fetal bradycardia, which was resolved after treatment with levothyroxine sodium hydrate. We suggest that congenital 
hypothyroidism should be included in the differential diagnosis in cases of fetal bradycardia without cardiac anomalies or maternal autoimmune diseases.

\section{Acknowledgments}

This work was supported by Grants-in-Aid for Young Scientists (grant number: 19K20194) of JSPS KAKENHI, the Practical Research Project for Intractable Diseases from Japan Agency for Medical Research and Development, AMED (19ek0109265h0003), and Nihon University Research Grant for Social Implementation for 2019. The authors received no other financial support for the research, authorship, and publication of this article.

\section{Author Contributions}

A.N. and N.N. wrote the case report and discussion section of the manuscript. R.A., M.H., K.F., A.S., K.K., R.K. and A.O. contributed to the care provided during the hospital course. N.N. and I.M. interpreted the clinical data. I.M. critically reviewed the manuscript and assisted with editing. All authors contributed to the intellectual content of this manuscript and approved the final version of the manuscript for submission.

\section{Conflict of Interest}

The authors declare no conflict of interest.

\section{References}

Beltrao, C.B., Juliano, A.G., Chammas, M.C., Watanabe, T., Sapienza, M.T. \& Marui, S. (2010) Etiology of congenital hypothyroidism using thyroglobulin and ultrasound combination. Endocr. J., 57, 587-593.

Burrow, G.N., Fisher, D.A. \& Larsen, P.R. (1994) Maternal and fetal thyroid function. N. Engl. J. Med., 331, 1072-1078.

Fisher, D.A. (1997) Fetal thyroid function: diagnosis and management of fetal thyroid disorders. Clin. Obstet. Gynecol., 40, 16-31.

Fisher, D.A. \& Klein, A.H. (1981) Thyroid development and disorders of thyroid function in the newborn. N. Engl. J. Med., 304, 702-712.

Izmirly, P.M., Saxena, A., Kim, M.Y., Wang, D., Sahl, S.K., Llanos, C., Friedman, D. \& Buyon, J.P. (2011) Maternal and fetal factors associated with mortality and morbidity in a multi-racial/ethnic registry of anti-SSA/Ro-associated cardiac neonatal lupus. Circulation, 124, 1927-1935.

Jaeggi, E. \& Öhman, A. (2016) Fetal and neonatal arrhythmias. Clin. Perinatol., 43, 99-112.

Kara, S., Tayman, C., Tonbul, A., Andiran, N., Tatli, M. \& Türkay, S. (2013) Congenital hypothyroidism presenting with postpartum bradycardia. J. Coll. Physicians Surg. Pak., 23, 214215.

Kleinman, C.S. \& Nehgme, R.A. (2004) Cardiac arrhythmias in the human fetus. Pediatr. Cardiol., 25, 234-251.

LaFranchi, S.H. \& Austin, J. (2007) How should we be treating children with congenital hypothyroidism? J. Pediatr. Endocrinol. Metab., 20, 559-578.

Macones, G.A., Hankins, G.D., Spong, C.Y., Hauth, J. \& Moore, T. (2008) The 2008 National Institute of Child Health and Human Development workshop report on electronic fetal monitoring: update on definitions, interpretation, and research guidelines. Obstet. Gynecol., 112, 661-666.

Marzuillo, P., Grandone, A., Perrotta, S., Ruggiero, L., Capristo, C., Luongo, C., Miraglia Del Giudice, E. \& Perrone, L. (2016) Very early onset of autoimmune thyroiditis in a toddler with severe hypothyroidism presentation: a case report. Ital. J. Pediatr., 42, 61.

Miyai, K., Mizuta, H., Amino, N., Tanizawa, O., Nose, O. \& Oura, T. (1979) Fetal heart-rate in congenital hypothyroidism. Lancet, 2, 693-694.

Öner, T., Ozdemir, R., Doksoz, O., Yozgat, Y., Karadeniz, C., Demirpence, S., Yilmazer, M.M., Buyukinan, M., Mese, T. \& Tavli, V. (2015) Cardiac function in newborns with congenital hypothyroidism: association with thyroid-stimulating hormone levels. J. Clin. Res. Pediatr. Endocrinol., 7, 307-311.

Vulsma, T., Gons, M.H. \& de Vijlder, J.J. (1989) Maternal-fetal transfer of thyroxine in congenital hypothyroidism due to a total organification defect or thyroid agenesis. N. Engl. J. Med., 321, 13-16. 